\title{
Incidental hepatic tuberculosis during planned resection of locally advanced ampullary carcinoma: a case report
}

Vee Chuan Hoe ${ }^{1}$, Allim Khairuddin', Jun Sam Tan', Mohd Sharifudin Sharif², Nornazirah Azizan³ and

Firdaus Hayati ${ }^{4^{*}}$ (D)

\begin{abstract}
Background: Tuberculosis (TB) is classified according to the site of disease as pulmonary or extrapulmonary. Extrapulmonary TB is less common than its counterpart in which it can be found anywhere in the body including the liver. Similar to ampullary carcinoma, TB liver can manifest with jaundice and deranged liver function tests, particularly in the obstructed biliary systems.

Case presentation: A 43-year-old gentleman with locally advanced ampullary carcinoma was noticed to have multiple suspicious liver nodules intraoperatively during curative ampulla resection. The surgery was then abandoned after a biopsy. The histology was consistent with chronic granulomatous inflammation. He was then subjected to a Whipple pancreaticoduodenectomy procedure after initiation of anti-tubercular treatment. He recovered well with no evidence of tumour recurrence and worsening TB.
\end{abstract}

Conclusions: $\mathrm{A}$ high index of suspicion and quick decision making can help to diagnose a possible extrapulmonary TB masquerading as a malignant disease in a patient with curative intention of ampullary carcinoma.

Keywords: Ampullary carcinoma, Hepatic metastasis, Hepatic tuberculosis, Case report

\section{Background}

Ampullary carcinomas are neoplasms that arise within the ampulla of Vater, distal to the bifurcation of the common bile duct (CBD) and pancreatic duct. The most prevalent initial presenting symptom is obstructive jaundice, caused by compression of the distal bile duct. Elevated liver function test (LFT) may reflect the site of disease; involvement of the biliary ducts of porta can be reflected by elevated levels of alkaline phosphatase (ALP) and gamma-glutamyl transferase, whereas high transaminases levels may reflect the rare involvement of the liver parenchyma. Furthermore, helical computed

\footnotetext{
* Correspondence: firdaushayati@gmail.com

${ }^{4}$ Department of Surgery, Faculty of Medicine and Health Sciences, Universiti Malaysia Sabah, Kota Kinabalu, Sabah, Malaysia

Full list of author information is available at the end of the article
}

tomography (CT) scanning demonstrates local tumour invasion and, more importantly, any presence of distant metastases, which most frequently involve the lymph nodes, peritoneum, and liver [1].

Similar to ampullary carcinoma, tuberculosis (TB) liver can present with jaundice and deranged liver function tests particularly in the obstructed biliary systems [2]. CT imaging in TB liver may demonstrate similar intrahepatic lesions such as macroscopic and microscopic nodules, abdominal lymphadenopathy as well as ascites [3]. Although careful evaluation of associated symptoms and signs can often lead to the correct diagnosis, it is difficult to determine the absolute nature of any liver lesions. We highlight a 43-year-old gentleman with locally advanced ampullary carcinoma for a definitive surgery

(c) The Author(s). 2020 Open Access This article is licensed under a Creative Commons Attribution 4.0 International License, which permits use, sharing, adaptation, distribution and reproduction in any medium or format, as long as you give appropriate credit to the original author(s) and the source, provide a link to the Creative Commons licence, and indicate if changes were made. The images or other third party material in this article are included in the article's Creative Commons licence, unless indicated otherwise in a credit line to the material. If material is not included in the article's Creative Commons licence and your intended use is not permitted by statutory regulation or exceeds the permitted use, you will need to obtain permission directly from the copyright holder. To view a copy of this licence, visit http://creativecommons.org/licenses/by/4.0/ The Creative Commons Public Domain Dedication waiver (http://creativecommons.org/publicdomain/zero/1.0/) applies to the data made available in this article, unless otherwise stated in a credit line to the data. 
with an accidental intraoperative finding of TB liver and discuss our approaches.

\section{Case presentation}

A 43-year-old gentleman presented with a 4-month history of painless jaundice with tea-coloured urine and loss of weight. He did not have any fever, night sweats, cough or other respiratory symptoms. He denied taking alcohol, having history of blood transfusion, past medical or family history of malignancy and pulmonary TB contact. On examination, he was icteric with no stigmata of chronic liver disease. There was no abdominal mass or tenderness felt. Biochemical investigation results revealed a serum total bilirubin of 45 , direct bilirubin of 31 (normal: $3-22 \mu \mathrm{mol} / \mathrm{L}$ ), ALP of 258 (normal: $30-120$ $\mathrm{mg} / \mathrm{dL}$ ), and cancer antigen (CA) 19-9 of 2061 (normal: 0-37 U/mL). Besides, inflammatory markers also were obtained showing serum C-reactive protein of 132.5 (normal range: $0-5 \mathrm{mg} / \mathrm{L}$ ) and erythrocyte sedimentation rate of 106 (normal range: $1-13 \mathrm{~mm} / \mathrm{Hr}$ ). As ultrasound abdomen showed a periampullary mass, an oesophagogastroduodenoscopy was done showing an ulcerated mass at the ampulla. The biopsy was consistent with adenocarcinoma. A staging CT demonstrated a periampullary mass with cystic lesions located at the periphery of the liver suggestive of liver cysts.

The patient underwent an elective Whipple pancreaticoduodenectomy procedure with definitive intention to resect the tumour. However, upon entry into the abdominal cavity, there were multiple solid nodules visualized on the surface of both liver lobes (Fig. 1). Since there was no frozen section facility available during that time, an immediate decision was made to abandon the surgery with a possibility of liver metastasis. Hence, a biopsy was undertaken. The biopsy of the liver nodules revealed a chronic granulomatous inflammation giving an

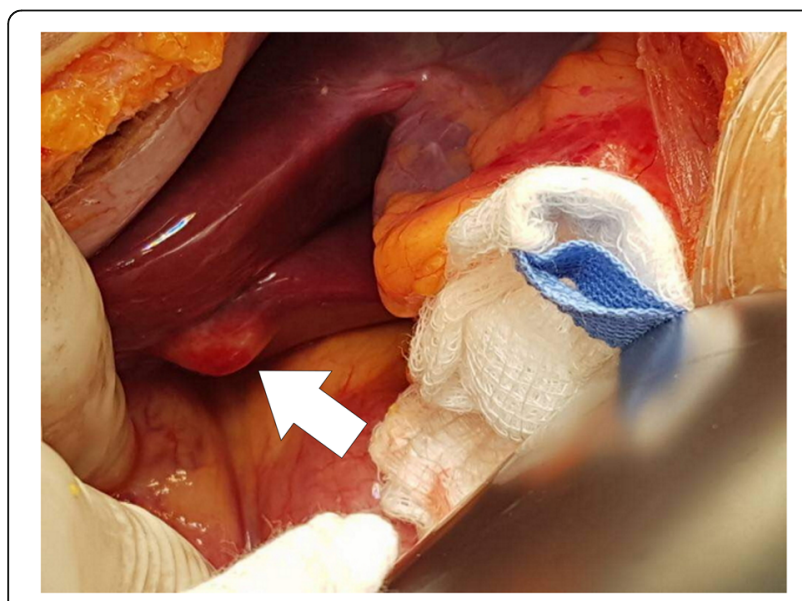

Fig. 1 One among the multiple solid nodules (arrow) was identified on the liver surface which was biopsied impression of extrapulmonary TB (Fig. 2) He was then started on anti-tubercular treatment (ATT) after discussion with the infectious disease team.

The patient underwent a Whipple procedure on day 8 of ATT. The surgery went well without any perioperative complications. He was discharged well on postoperative day 10. The histopathological report showed a moderately-differentiated adenocarcinoma with negative resection margins. During follow-up at 1-month postsurgery, repeat CT scan showed no residual lesion within the residual body and tail of the pancreas and the previously seen hypodense hepatic lesions were reduced in number and size (Fig. 3). Subsequent follow-up CT scans demonstrated no local recurrence and absent hepatic lesions (Fig. 4). To support his remarkable recovery, his CA 19-9 had reduced to 65.8 (normal: 0-37 U/mL).

\section{Discussion and conclusions}

The prognosis of ampullary carcinoma is guarded if neglected. The only potentially curative treatment for ampullary carcinoma is Whipple pancreaticoduodenectomy. Although the surgery traditionally has been associated with relatively high negative outcomes, advances in operative techniques, anaesthetic management and vigorous postoperative care have led to significant improvements in outcomes with a 5-year survival rate of 70\% [4, 5]. Individuals who have advanced locoregional or metastatic disease, however, carry a poorer prognosis. In fact, the 1-year survival rate after resection of the ampullary tumour and hepatic metastases is found to be $13 \%$ with a median overall survival of 5.9 months [6]. Therefore, patients' selection and cancer staging determination prior to definitive surgery are crucial. In our case, a quick decision was made by getting a tissue biopsy intraoperatively before proceeding to such surgery. If the

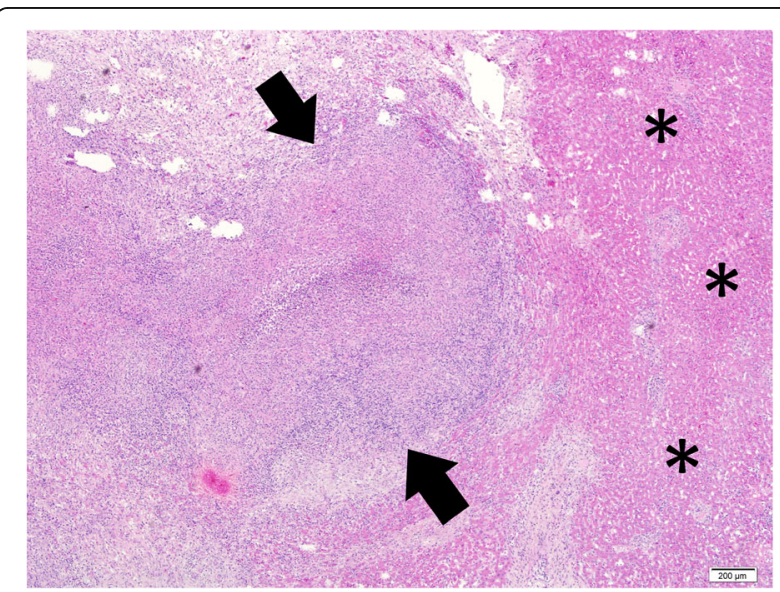

Fig. 2 Liver biopsy showing microscopic evidence of granuloma formation (arrow). Note the presence of liver parenchyma at the periphery $\left(^{*}\right)$ (Haematoxylin and eosin stain, original magnification $\times 4$ ) 


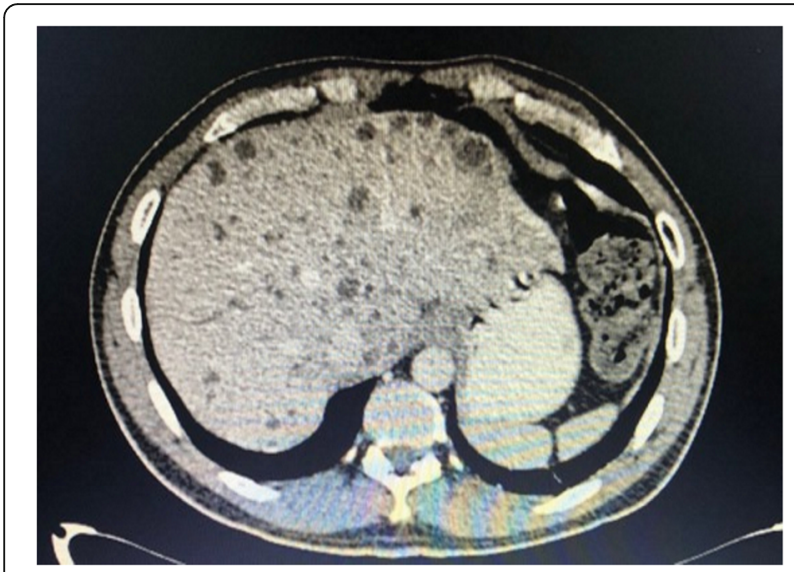

Fig. 3 Multiple hypodense hepatic lesions which represent TB liver noted on both sides of liver lobe

biopsy turns out to be malignant, the stage of disease will be advanced. Luckily, our biopsy revealed a TB liver.

Tuberculosis is endemic in Asia especially in Malaysia with $11 \%$ of the cases of extrapulmonary TB [7]. TB liver is reported to exist in $50-80 \%$ of patients who are dying of pulmonary TB [8]. On the contrary, primary TB liver is considered to be rare and constitutes less than $1 \%$ of all cases [9]. The spread of hepatic tuberculosis can be attributed by hematogenous spread from active pulmonary $\mathrm{TB}$, swallowing of infected sputum in the active lung disease and ingestion of infected food products. Classification of liver TB has remained in dispute even until now but many authors agree with the existence of the following 3 types namely nodular tuberculosis, military tuberculosis, and mixed tuberculosis [3]. Clinical presentation is extremely varied and often involves abdominal pain, abdominal mass, nausea and vomiting, jaundice, hepatomegaly, ascites, anorexia, and weight loss. This presents a particular diagnostic challenge to clinicians as the diverse features of the disease can mimic many

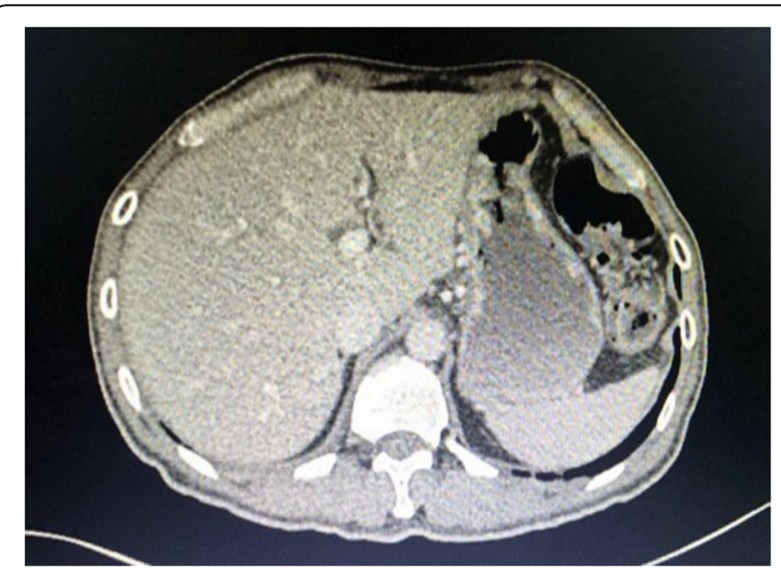

Fig. 4 Resolution of TB liver on CT imaging after 6 months post ATT conditions, including malignancy, systemic infections, and viral hepatitis including TB.

TB liver is a treatable disease and the approach to ATT for it is similar to the extrapulmonary TB. A combination of drugs may be given as part of a 9 to a 12month regimen consisting of 4 first-line drugs (rifampicin, isoniazid, pyrazinamide, and ethambutol) [10]. They are given in 2 phases namely intensive phase (first 2 months) and maintenance phase (next 3 month and beyond) [7]. In order to avoid non-compliance towards ATT, the initiation of fixed dosage such as Akurit-4 and directly observed therapy short-course has improved its delivery.

The current patient case is an explicit example of a rare form of TB masquerading as a liver metastasis occurring with a locoregional ampullary tumour. The correct diagnosis was so important in this case because both aetiologies if treated erroneously, might lead to accelerated morbidity and mortality. In the absence of histopathological examination, the patient may have been misdiagnosed with distant metastasis involvement of the liver and treated differently in view of the poor prognosis that metastatic ampullary carcinoma carries. On the contrary, with the correct diagnosis of both conditions, the patient can be treated with favourable results. Therefore, some investigators have supported the use of diagnostic laparoscopy as a method to stage and assess resectability of metastatic disease prior to resection [11]. This is important because this can minimize hospitalization and postoperative complications.

In conclusion, liver tuberculosis, although rare, can mimic primary or metastatic hepatic tumour. Therefore, a high clinical suspicion is required to recognize this possibility while evaluating ampullary cancer patients with hepatic lesions, especially in TB endemic regions. Thus, early diagnosis and immediate treatment of $\mathrm{TB}$ can be initiated and at the same time, any surgical procedure can be carefully planned with fewer complications. However, there are no protocols for this type of case, therefore treatment should be tailored to each scenario.

\section{Abbreviations \\ TB: Tuberculosis; CBD: Common bile duct; LFT: Liver function test; ALP: Alkaline phosphatase; CT: Computed tomography; CA: Cancer antigen; ATT: Anti-tubercular treatment}

\section{Acknowledgements}

We would like to thank the Director General of Health Malaysia for his permission to publish this article as a case report.

\section{Authors' contributions}

AK conducted the literature search and drafted the manuscript. AK, VCH, and FH contributed to the conception and design of the work. AK, VCH, JST and MSS were involved in the management of the patient. NA provided the histopathological figures. All authors reviewed the manuscript and gave approval for publication of the final version. 


\section{Funding}

The study did not receive any funding.

\section{Availability of data and materials Not applicable.}

Ethics approval and consent to participate

No ethical clearance required as it only involves a case report.

\section{Consent for publication}

Written and signed informed consent for publication of this case was obtained from the patient, including radiologic and intraoperative pictures. A copy of the consent document can be provided upon request.

\section{Competing interests}

The authors have no conflict of interests to declare.

\section{Author details}

'Department of Surgery, Queen Elizabeth Hospital, Ministry of Health Malaysia, Kota Kinabalu, Sabah, Malaysia. ${ }^{2}$ Gleneagles, Kota Kinabalu, Sabah, Malaysia. ${ }^{3}$ Department of Pathobiology and Medical Diagnostic, Faculty of Medicine and Health Sciences, Universiti Malaysia Sabah, Kota Kinabalu, Sabah, Malaysia. ${ }^{4}$ Department of Surgery, Faculty of Medicine and Health Sciences, Universiti Malaysia Sabah, Kota Kinabalu, Sabah, Malaysia.

Received: 6 April 2020 Accepted: 23 June 2020

Published online: 30 June 2020

\section{References}

1. Bakkevold KE, Arnesjø B, Kambestad B. Carcinoma of the pancreas and papilla of Vater: presenting symptoms, signs, and diagnosis related to stage and tumour site. A prospective multicentre trial in 472 patients. Norwegian pancreatic Cancer trial. Scand J Gastroenterol. 1992;27(4):317-25.

2. Hickey AJ, Gounder L, Moosa MY, Drain PK. A systematic review of hepatic tuberculosis with considerations in human immunodeficiency virus coinfection. BMC Infect Dis. 2015;15:209.

3. Yu RS, Zhang SZ, Wu JJ, Li RF. Imaging diagnosis of 12 patients with hepatic tuberculosis. World I Gastroenterol. 2004;10(11):1639.

4. Di Giorgio A, Alfieri S, Rotondi F, Prete F, Di Miceli D, Ridolfini MP, et al. Pancreatoduodenectomy for tumors of Vater's ampulla: report on 94 consecutive patients. World J Surg. 2005;29(4):513-8.

5. Beger HG, Treitschke F, Gansauge F, Harada N, Hiki N, Mattfeldt T. Tumor of the ampulla of Vater: experience with local or radical resection in 171 consecutively treated patients. Arch Surg. 1999;134:526-32.

6. Gleisner AL, Assumpcao L, Cameron JL, Wolfgang CL, Choti MA, Herman JM, et al. Is resection of periampullary or pancreatic adenocarcinoma with synchronous hepatic metastasis justified? Cancer. 2007;1 10(11):2484-92.

7. Sultan MAH, Hayati F, Azizan N, Haur LC, Sharif SZ. Various presentations of breast tuberculosis and tuberculous lymphadenopathy: a case series of surgical rarity. Med Med J. 2017;32(1):33-41.

8. Hussain W, Mutimer D, Harrison R, Hubscher S, Neuberger J. Fulminant hepatic failure caused by tuberculosis. Gut. 1995;36:792-4.

9. Chong VH. Hepatobiliary tuberculosis: a review of presentations and outcomes. South Med J. 2008;101:356-61.

10. Jullien S, Jain S, Ryan H, Ahuja V. Six-month therapy for abdominal tuberculosis. Cochrane Database Syst Rev. 2016;11:CD012163.

11. Conlon KC, Dougherty E, Klimstra DS, Coit DG, Turnbull AD, Brennan MF. The value of minimal access surgery in the staging of patients with potentially resectable peripancreatic malignancy. Ann Surg. 1996;223(2):13440

\section{Publisher's Note}

Springer Nature remains neutral with regard to jurisdictional claims in published maps and institutional affiliations.

Ready to submit your research? Choose BMC and benefit from:

- fast, convenient online submission

- thorough peer review by experienced researchers in your field

- rapid publication on acceptance

- support for research data, including large and complex data types

- gold Open Access which fosters wider collaboration and increased citations

- maximum visibility for your research: over $100 \mathrm{M}$ website views per year

At BMC, research is always in progress.

Learn more biomedcentral.com/submissions 